\title{
CONSTRAINTS EXPERIENCED BY VETERINARIANS WHILE PERFORMING THEIR DUTIES
}

\author{
TC Ratnayake ${ }^{1 *}$, PVK Sasidar $^{2}, \mathrm{~J} \mathrm{Gupta}^{2}$ and BS Meena ${ }^{2}$ \\ ${ }^{1}$ Department of Animal Production \& Health, Sri Lanka \\ ${ }^{2}$ Indira Gandhi National Open University, India/ Division of Dairy Extension, National Dairy Re- \\ search Institute, Karnal, Haryana
}

Accepted: $13^{\text {th }}$ May 2015

\begin{abstract}
A study was conducted to identify various constraints which hinder the role performances of Veterinary Assistant Surgeons (VASs) of Andhra Pradesh in India. Data were collected from 220 respondents in eleven selected districts through specially prepared schedule and subjected to analyze through Garrett's ranking technique to draw valid inferences. The study revealed that arbitrary target fixation for artificial insemination with a mean score of 68.38 was the most important constraint followed by non separation of contagious animals with a mean score of 68.03 as the second important constraint. Insufficient policies and regulations, lack of awards and rewards, veterinary dispensaries are not well equipped and discussion on field problems getting low priority in the meetings were perceived as other crucial constraints by VASs and need to be mitigated. All these constraints are very critical and addressing them would go a long way in increasing the effectiveness of the services provided by the veterinarians. This investigation has an organizational and social significance for development of livestock organizations not only in India, but also to other SAARC countries as well.
\end{abstract}

Key words: Constraints, Extension, Performance, Ranking

\section{INTRODUCTION}

Livestock is one of the important enterprises that represents a major segment of the food industry, which supports the rural households by providing gainful employment and steady income. Hence, the Government of India and State governments' policies on agricultural development seek to ensure the welfare of the vast majority of people living in the rural areas; and stress towards the social justice and equality of opportunities as an important consideration in the development strategy. This is attempted through many state and non-state organizations. State governments have set up separate departments, which are responsible for development of animal husbandry and dairying in the state. The mandate given to state Animal Husbandry Department (AHD) is to build the health of the nation by increasing the availability of animal origin foods like

*Corresponding author: talata.rupasinghe@gmail.com milk, meat and eggs to human population; through scientific breeding, feeding and disease management of livestock. Therefore, there is no doubt that veterinarians working in the state AHD have a very special role to play as main actors and partners to the industry in undertaking developmental activities. However, persisting poor productivity and quality of livestock production is still a main concern in India. Therefore, the growing needs of high-level performers and competent employees have put tremendous pressure on animal husbandry organizations. Department of Animal Husbandry, Andhra Pradesh, which is one of the most rapidly improving organizations of livestock development in India, is no exception for this. Constraints are elements, factors, or subsystems that restricts an entity, from achieving its potential (or higher level of output) with reference to its goal (Rahman, 2011). In any working condition existence of constraints is a common feature. Therefore, it 
has become vital to identify and prioritize the factors or reasons that hamper the performance of Veterinary Assistant Surgeons (VASs) to imply remedial measure for making them more effective and efficient.

Hence, an effort had been made to collect the constraints faced by the field veterinarians of AHD in Andhra Pradesh. From the range of analysis presented on various kinds of constraints which hinder the performance of veterinarians, the policy makers, directors and other officials in state AHD, at different levels can make a choice which is appropriate for their circumstances.

\section{MATERIALS AND METHOD}

The state of Andhra Pradesh in southern region was purposively selected for the proposed study. A total of eleven (11) districts were selected from each geographical region i.e. four (4) from Andhra, five (5) from Telangana and two (2) from Rayalaseema so as to represent areas differing in socio-economic and working factors. Data were collected by survey method from 220 VASs taking 20 respondents randomly from each district (Figure 1).

A constraint for the present study was operationalized as certain forces which may be social, psychological, infrastructural, managerial, communicational, technological and institutional operating singly or in conjunction with each other and impeding the VASs in carrying out their day to day activities pertaining to successful livestock development. Schedule was specially prepared for this study. Lists of constraints were prepared through informal discussions with the field extension personal as well as VASs of AHD. To make this list more comprehensive, items collected from literature, experts, field personal and scientists were also included. The items were later categorized under the headings of social, psychological, infrastructural, managerial, communicational, technological and institutional areas. Garrett's ranking technique was used.

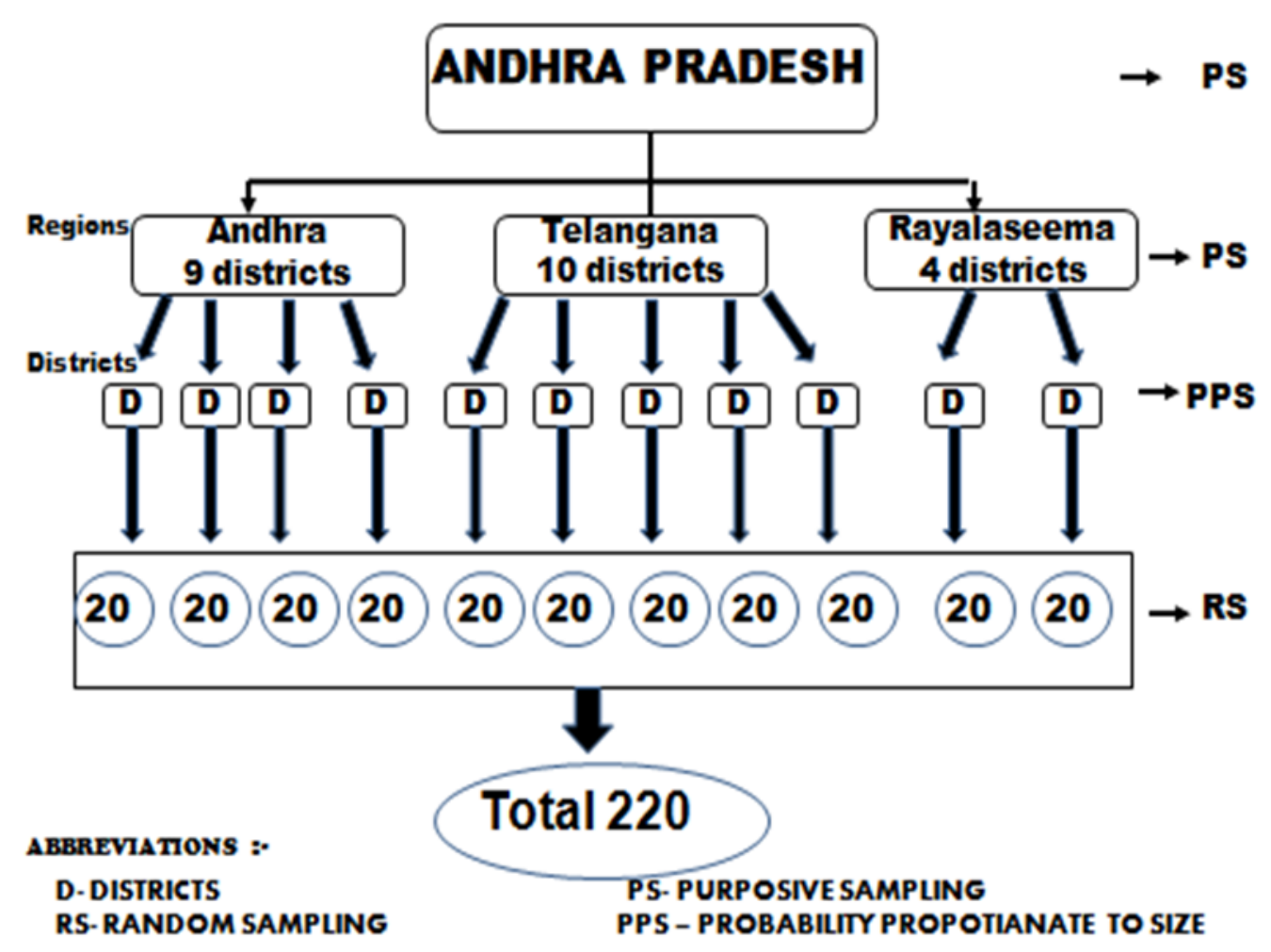

Figure 1 : Sampling Plan 
The respondents were asked to assign rank to different constraints with respect to their opinion. The order of the merit given by the re-

Percent position $=\frac{\mathbf{1 0 0}(\mathbf{R i j}-\mathbf{0 . 5 0})}{\mathrm{Nj}}$

spondents' was changed into ranks by using the formula:

Where

$\mathrm{R}=$ Rank given for $\mathrm{i}^{\text {th }}$ item by $\mathrm{j}^{\text {th }}$ individual $\mathrm{N}=$ Number of items ranked by $\mathbf{j}^{\text {th }}$ individual

The percent position of each rank was converted into scores (Garrett, 1981). For each factor, the scores of individual respondents were added together and divided by the total number of the respondents. The mean scores for all the factors were ranked by arranging in descending order.

\section{RESULTS AND DISCUSSION Identification of Constraints}

Frequently occurring constraints under the sub -heads of social, psychological, infrastructural, managerial, communicational, technological, and situational were identified and presented in the Tables 1-7.

\section{Social Constraints}

The ranking pattern of social constraints in the Table 01 in combination probably gave an overall picture of the social system prevailed in the state in respect to livestock development. Out of the total nine constraints, "non separation of contagious animals" emerged as most important as the rest. Since the diseases are to be prevented and causes are to be eliminated at the source itself, the importance of separation of contagious animals needs no explanation. The fact that many farmers rear animals with limited space and no interest has been given to such type of healthy measurement made the situation worst reported many a times. Therefore respondents' strong expression in this regards were quite logical. With regards to the second and third priority, village organizations are less involved in promoting dairying and misguidance of quacks was also understandable. Findings of Saharia (1990), who also reported that village organizations are not attracted in dairying and misguidance of quacks as important constraints to the sustainable dairy farming as perceived by veterinarians in the state of Assam support the finding of the present study. Surprisingly, that respondent did not put more emphasis on “farmers' preference natural service over artificial insemination (AI)". It implied that farm-

Table 1: Ranking pattern on social constraints

\begin{tabular}{clcc}
\hline $\begin{array}{c}\text { SI } \\
\text { No. }\end{array}$ & \multicolumn{1}{c}{ Constraints } & $\begin{array}{c}\text { Mean } \\
\text { Score }\end{array}$ & Rank \\
\hline 1 & Non separation of contagious animals & 68.03 & I \\
2 & $\begin{array}{l}\text { Village organizations are less involved in promoting } \\
\text { dairying }\end{array}$ & 58.12 & II \\
3 & Misguidance by quacks & 55.98 & III \\
4 & Farmers preference for natural service over A.I & 54.75 & IV \\
5 & Lack of farmers faith on modern veterinary medicine & 53.64 & V \\
6 & Farmers interest are for keeping local bulls un-castrated & 49.03 & VI \\
7 & $\begin{array}{l}\text { Farmers are less interested in cultivation of } \\
\text { improved/hybrid varieties of fodder crops }\end{array}$ & 43.70 & VII \\
8 & $\begin{array}{l}\text { Farmers give more importance to bullocks than dairy } \\
\text { animals }\end{array}$ & 36.54 & VIII \\
9 & $\begin{array}{l}\text { Performance of pregnancy test considered as against social } \\
\text { norms, by farmers }\end{array}$ & 30.37 & IX \\
\hline
\end{tabular}


ers in Andhra Pradesh have more faith on AI to get their cows pregnant. This situation is quite natural with present accelerated breeding programs with expanding facilities for AI spread in the state. Therefore result in this regards were in accordance with the expectations.

\section{Psychological Constraints}

In general, it is assumed that in the context of human behavior there is no end to psychological constraints. (Saharia, 1990). Among the seven specific constraints incorporated under this category, lack of awards and rewards emerged as most important with mean score of 63.15 (Table 02). Every employee expects that his/her work should be recognized in one way or another. What an employee wants is that solid proof that, their superiors really cares about the job they do. Better recognition of one's work would encourage employee to perform better. It was clear from these observations that the department had no perspective rewards for the VASs in recognition of their good performance. This finding is in agreement with literature (Sharma,1980; Acharya, 1984; Nataraju and Channegowda, 1986; Nayaket al., 1986;Thippeswamaiah, 1991; Nagananda, 2005 and Sandika, et al., 2007).

From the table 02 it was evident that poor accessibility to professional development ranked second among them. The professional development opportunities are highly ne- glected in AHD as perceived by respondents of the study. The importance of competency as well as professional capacity needs no explanation. This particular constraint with a mean of 62.13 clearly suggests the need for upgrading the professional competency of the staff by giving them opportunities to prosecute higher studies. The organizational support to an individual's career and personal affairs is more vital than monetary or other material rewards and reduces turnover of employees (Blau, 2001).Training at one time had a restricted meaning of education; in the modern industry the term has become much broader, purely indicating efforts to develop sensory- motor proficiencies. This result is in conformity with findings of Venkatasubramaniam and Ramchand (1992) and Punjabi et al. (2005). The third among the psychological constraints which had its mean score 59.51. It was also inferred that with a brighter promotional opportunities VASs could improve his/her status both in organization and society. Promotion is upward growth in one's job hierarchy as a consequence of human capital investment, recognition of past performance and an incentive for future performance (Ahmed et al, 2010). Moreover, it is the probability of winning prize and an outcome of revealed ability of worker at his job (Lazear \& Rosen, 1981). It satisfied the need for recognition and serves as a great motivator of job performance. Moreover, the poor promotional opportunities in the animal husbandry department made the VASs to rate this particular con-

Table 2: Ranking pattern on psychological constraints

\begin{tabular}{clcc}
\hline $\begin{array}{c}\text { Sl } \\
\text { No. }\end{array}$ & \multicolumn{1}{c}{ Constraints } & $\begin{array}{c}\text { Mean } \\
\text { Score }\end{array}$ & Rank \\
\hline 1 & Lack of awards and rewards & 63.15 & I \\
2 & Poor accessibility to professional development & 62.13 & II \\
3 & Less avenue for promotions & 59.51 & III \\
4 & Lack of motivation for veterinarians & 49.72 & VI \\
5 & High pedigreed animals invite complications & 47.71 & V \\
6 & Lack of affection for crossbred animals & 38.88 & VI \\
7 & Lack of good rapport with farmers & 32.99 & VII \\
\hline
\end{tabular}


straint as an important psychological constraint. The VASs were dissatisfied with their promotional opportunities. Hence, the present study brings out the urgent need for policy makers and administrators to make avenues for prompt promotions.

These results are in line with the findings of Sharma (1980), Acharya (1984), Nataraju and Channegowda (1986), Nayaket al. (1986),Nagananda (2005), Naganandaet al. (2006) and Sandikaet al.( 2007).

In the rest of the psychological constraints, the respondents have almost randomly distributed in all the degrees without showing any specific degree for any of the left out areas.

\section{Infrastructural Constraints}

A perusal of the table 03 reveals that VASs of the study area perceived that shortage of equipments as the most important constraint to them. The depth of truth in this regard was realized by the researcher herself at the time of data collection, the dispensaries were running short of equipments like syringe, needles, sterilization sets and other accessories. It was observed that most of the dispensaries were not equipped with essential surgical equipments. Though the VASs had the skill to perform minor operations and even dairy farmers were ready to bear the expenses as the increased value of livestock, the VASs could not perform those due to lack of proper surgical equipments. These findings are in confirmation with Saharia (1990), Badhulal (1999) Ravikumaret al. (2005) and Punjabi et al. (2005). Lack of conveyance for VASs was the second major constraint as perceived by VASs. The VASs were not provided with a vehicle and also not given any travel allowance. The findings of Saharia (1990), Thippeswamaiah (1991), Rath, (1992), Bosco (2000), Popat et al. (2002), Nagananda (2005) and Punjabi et al. (2005) and Biradar (2009)also fit well in this line.

Lack of conveyance for VASs and limited supplies of resources not only makes the impossibility of door step service, but also hinder their capacity to address situations in the field. Improper storage facilities for medicines and vaccines in the dispensaries were also identified as important by the respondents. This reflected that non availability of refrigerators and proper cupboards to store vaccine and medicines in the dispensaries. A careful analysis of the fact revealed that in most of the dispensaries inadequacy of essential furniture was noticed. This finding gets support from the studies of Saharia (1990), Popat et al. (2002), Chanderet al. (2003), and Sawant and Nikam (2007).

Lack of adequate staff secured fourth place under the infrastructural constraints. In fact, there were severe shortages of para-

Table 3: Ranking pattern on infrastructural constraints

\begin{tabular}{clcc}
\hline $\begin{array}{c}\text { SI } \\
\text { No. }\end{array}$ & \multicolumn{1}{c}{ Constraints } & $\begin{array}{c}\text { Mean } \\
\text { Score }\end{array}$ & Rank \\
\hline 1 & Ill-equipped dispensaries & 63.08 & I \\
2 & Lack of conveyance for VASs & 62.98 & II \\
3 & Improper storage facilities for medicines and vaccines & 57.97 & III \\
4 & Lack of adequate staff & 49.72 & VI \\
5 & Poor infrastructure facilities & 44.52 & V \\
6 & Lack of facilities for veterinary service at farmers door & 37.55 & VI \\
7 & Delayed reporting of disease & 30.76 & VII \\
8 & Instability of Veterinarians in their working place & 18.48 & VIII \\
& & & \\
\hline
\end{tabular}


veterinarians to assist the veterinarians and also lack of attendants too. Lack of adequate skilled subordinate staff in the livestock service delivery system in the recent past had been a matter of serious concern. Therefore, if the feeling of the VASs could be considered as the true reflection of the gravity of the situation, this constraint should alarm the authority to take necessary steps so that, efficient livestock service could become accessible to the poor livestock farmers. The finding of inadequate supporting staff at field level of the present study are in confirmation with the literature (Rao and Sastri, 1984; Sohal, 1985; Badhulal, 1999; Punjabi et al., 2005;Ravikumaret al., 2005 and Biradar, 2009).

In the rest of the constraints under the category of infrastructural, respondents were almost equally distributed in all frequencies without showing any specific degree.

\section{Managerial Constraints}

Out of the ten specific constraints (Table 04) on which the respondents were asked to rank according to their priority, the 3 constraints received maximum priority were:

Inadequate policies and regulations

Inadequacy of front line field officers

Little or no participation in programme planning

Majority of the respondents considered that lack of policy and regulations were the major constraints pertaining to the managerial aspects. While there is increasing demand for livestock products, underprivileged can take benefit only after they overcome economic, technological and social constraints (Thomas and Rangnekar, 2004). To be able to do so they need strong support of appropriate research and extension as well as strong livestock policy. The results reported by earlier researchers (Rao and Sastri, 1984; Sohal, 1985 and Biradar 1986) are in line with the findings of the present study. The second most important managerial constraint with a mean score of 58.00, inadequacy of front line field officers indicated lack of manpower. Several veterinary positions were vacant, with the result that one VAS was simultaneously handling more than 2 or 3 animal health centers. The third important managerial constraint was little or no participation in program planning. In many cases the VASs were not consulting, and targets were fixed by the administrators which led to unrealistic targets. Given an opportunity people in the organization would like to participate in decision making and goal setting procedure and expectedly would improve their role performance. The lower or modest participation of employees are not desirable for the success of any organization. Employee participation in decision making can be described as one of

Table 4 : Ranking pattern on managerial constraints

\begin{tabular}{clcc}
\hline $\begin{array}{c}\text { Sl } \\
\text { No. }\end{array}$ & \multicolumn{1}{c}{ Constraints } & $\begin{array}{c}\text { Mean } \\
\text { Score }\end{array}$ & Rank \\
\hline 1 & Inadequate policies and regulations & 65.36 & I \\
2 & Inadequacy of front line field officers & 58.00 & II \\
3 & Little or no participation in programme planning & 56.55 & III \\
4 & Few people get all benefits & 50.18 & IV \\
5 & Insufficient budget allocation for programme execution & 50.09 & V \\
6 & Lack of proper guidance in crisis situation & 50.01 & VI \\
7 & Lack of Monitoring and evaluation & 44.40 & VII \\
8 & Ideas, suggestions are not valued & 41.42 & VIII \\
9 & Lack of supervision & 41.35 & IX \\
10 & Week coordination among VASs & 30.29 & X \\
\hline
\end{tabular}


the most important, but least practiced concepts in the organizational development. Certainly, in public sector organizations particularly when most of its employees of different categories work in different places, participative decision making is a matter of distant proposition.

Therefore, there was no wonder that this particular constraint received third rank and this confirmed the importance of VASs involving in planning process. This result is in agreement with the findings reported by Venkatasubramaniam and Ramchand (1992).

In the rest of the constraints, the respondents were almost randomly distributed in all the degrees without showing any inclination for any specific degree for any of the left out areas.

\section{Communicational Constraints}

Like all process which involves human beings and their emotions, the process of communication is complicated, unpredictable and difficult to control. The constraints relating to this area were measured with 6 specific statements. The three prominent constraints perceived by the respondents receiving 63.08, 59.85 and 49.5 scores (Table 05) were, discussing field problems and get low priority in the meetings, no research extension dialogue and lack of feedback on performance were quite understandable. Realization of the fact that, most of the times the administrators did not realize the worth or importance of issues faced by field level functionaries in their respective field of operation. This situation was leading to the problems getting complicated with this ignorance and less interest. According to Vroom (1964), sensitivity of organizational management for well being of employees and supportiveness in their personal affairs at workplace has positive effect on the job satisfaction. The findings of Rao (1987) also fit well in this line. Switching into the second and third major communicational constraints, no research and extension linkage and lack of feedback on performance were quite logical. The problem of establishing effective research- extension linkage appears frequently in the literature. The World Bank (1985) identified the gap between research and extension as the most serious institutional problem to overcome in developing an effective research and extension system. There is need to pretest technologies and recommendations before wider application since these recommendations should not only be technologically sound, economically viable but should also be socially acceptable. Necessity of introducing technology is well understood. But this result highlighted the fact that need of strong research extension linkage in terms of identification needs and feedback of the farmers and also of modifying technologies and recommendations. Coming to the point of "lack of feedback", research findings over five decades has amply documented that feedback is an important means for increasing motivation, job

Table 5: Ranking pattern on communicational constraints

\begin{tabular}{llcc}
\hline $\begin{array}{c}\text { Sl } \\
\text { No. }\end{array}$ & \multicolumn{1}{c}{ Constraints } & $\begin{array}{r}\text { Mean } \\
\text { Score }\end{array}$ & Rank \\
\hline 1 & Discussing field problems get low priority in the meetings & 63.08 & I \\
2 & No research -extension dialogue & 59.85 & II \\
3 & Lack of feedback on performance. & 49.50 & III \\
4 & Lack of participativeness & 48.24 & IV \\
5 & Difficulties in communication for VAS posted in distant & 41.58 & V \\
& places & & \\
6 & Timely communication is not available & 37.75 & VI \\
\hline
\end{tabular}


satisfaction and role performance of the various kinds of employees. Feedback is the cheapest, most powerful yet, most under used management tool that we have at our disposal. VASs may have a great sense of direction but that may not be sufficient to keep them on track. They like to feel involved and identified with their organization. Feedback can help achieve that state. The realization that "lack of participativeness" was none other than just indication of the urgent need of participation and involvement in livestock development planning process. It truly reflected the situation where the planning was done by someone and responsibility for success was given to others who were not directly involved in the initial planning. Therefore it was mandatory for the VASs to accept all the shortcomings in planning which made him to rate this as an important constraint. These issues were matter of great concern for the department. These findings are partly in line with Venkatasubramaniam and Ramchand (1992).

\section{Technological Constraints}

Among the technological constraints, arbitrary target fixation for artificial insemination (AI) was the most serious constraint as perceived by VASs. The mean score was 68.38. In many cases the VASs were not consulted and targets were fixed by the administrators which lead to unrealistic targets. Therefore, no wonder that this constraint received high priority and this confirmed the importance of involving VASs in goal setting. This was in line with the observation of Venkatasubramanian and Ramchand (1992). Delayed reporting of heat secured third position. The success of $\mathrm{AI}$ is depend on a great extent on the proper time of insemination. The conception rate and number of calves born would be affected in case the farmers presented their animals for AI during late heat. This reflected upon the performance of VASs which might be a cause of concern to them. The other constraints felt by sizeable number of respondents were, lack of knowledge on dairy innovations among farmers (mean score 57.26), repeat breeding (mean score 56.53) and unhygienic milking (mean score 56.02), respectively. This also indirectly indicates the urgent need of monitoring, evaluation and proper extension set-up in study area. The constraint "repeat breeding" may be due to several factors such as improper time of insemination, poor health conditions and growth, psychological problems etc. This reflected upon the performance of VASs which might be a cause of concern for them. The above mentioned findings are in line with the finding of Saharia (1990) who also reported that delayed reporting of heat, unhygienic milking and repeat breeding were the major technological constraints as perceived by VASs in Assam. The findings of

Table 6: Ranking pattern on technological constraints

\begin{tabular}{clcc}
\hline $\begin{array}{r}\text { SI } \\
\text { No. }\end{array}$ & \multicolumn{1}{c}{ Constraints } & $\begin{array}{c}\text { Mean } \\
\text { Score }\end{array}$ & Rank \\
\hline 1 & Arbitrary target fixation for AI & 68.38 & I \\
2 & Delayed reporting of heat & 58.48 & II \\
3 & Lack of knowledge on dairy innovations among the farmers & 57.26 & III \\
4 & Repeat breeding & 56.53 & VI \\
5 & Unhygienic milking & 56.02 & V \\
6 & Supply of defective equipments & 39.83 & VI \\
7 & Outbreaks of different contagious diseases arises at the same & 39.17 & VII \\
& time & 34.06 & VIII \\
\hline
\end{tabular}


Venkatsubramaniam (1996) also fit well in this line.

\section{Situational Constraints}

Existing situation of any organization and its environment play a pivotal role in success or failure of any development program (Saharia, 1990). In this regard, among number of situational constraints included in this study, "high cost of dairy animals" was perceived as the most important by VASs as evident by its high mean score. This situation is quite logical. In economic theory, the law of supply and demand is considered as one of the fundamental principles governing an economy. It is described as the state where, as supply increases the price will tend to drop or vice versa, and as demand increases the price will tend to increase or vice versa. In this scenario, this indicated the fact that farmers' preference for crossbreds for milk production and increase of demand for high yielding cross bred animals might be the reason for that. Therefore the result in this regard was in accordance with the expectation. Indiscriminate breeding is another major constraint which pauses a serious question on breeding policy and view of VASs on this aspect needs immediate attention.

Keeping in view the multidimensionality of the VASs job, these findings provide an insight into the constraints that impede the efficient functioning of VASs; it also provides information of practical utility for the plan- ners, policy makers and administrators.

The above mentioned constraints are all very critical and addressing them would go a long way in increasing the effectiveness of the services provided by the veterinarians. However, in reality it is not possible to address all the constraints at the same time. Thus, it is important to understand a few issues which were regarded as most crucial by VASs. Therefore an attempt was made and found that some important constraints which need to be mitigated were arbitrary target fixation for AI, non separation of contagious animals, insufficient policies and regulations, lack of awards and rewards, dispensaries are not well equipped and discussion on field problems getting low priority in the meetings.

\section{CONCLUSION}

Constraints analysis would led to conclude that the major constraints faced by the veterinaries while performing their roles needs to be eliminated and due care should be taken by the concerned to ensure that such problems do not arise. Immediate measures should be taken by the AHD authorities to help the veterinarian to overcome the exiting constraints.

\section{ACKNOWLEDGEMENT}

The financial assistance for the first author, from the Council of Agricultural Research Policy (CARP), Sri Lanka is greatly acknowledged.

Table 7: Ranking pattern on situational constraints

\begin{tabular}{clcc}
\hline $\begin{array}{c}\text { Sl } \\
\text { No. }\end{array}$ & \multicolumn{1}{c}{ Constraints } & $\begin{array}{c}\text { Mean } \\
\text { Score }\end{array}$ & Rank \\
\hline 1 & High cost of dairy animals & 62.49 & I \\
2 & Indiscriminate breeding & 54.09 & II \\
3 & More emphasis on reports and records & 51.77 & III \\
4 & Frequency occurring of flood and droughts & 47.88 & IV \\
5 & Difficulty in disposing of male calves & 47.75 & V \\
6 & Lack of motivation for dairying in new generation & 45.28 & VI \\
7 & Delayed transportation and supply of essential items & 38.49 & VII \\
\hline
\end{tabular}




\section{REFERENCE}

Acharya RM 1984 Constraints in milk production enhancement in India. Diamond Jubilee Souvenir (1983-84), NDRI. Karnal.

Ahmad Z, Ali L, Ahmad N, Nawaz MM and Ahmed I 2010 Perception of Middle Level Managers Regarding Organizational Work Climate: An Exploratory Studyof Pharmaceutical Industry in Pakistan. Interdisciplinary Journal of Contemporary Research In Business. 2 (2).

Badhulal B 1999 An analysis of dairy farming practices among the tribal farmers of Khammam district of Andhra Pradesh. MVSc Thesis (Unpub.), Acharya N. G. Ranga Agricultural University, Rajendranagar, Hyderabad, India.

Biradar C 2009 Evaluation of Livestock Service Delivery by Different Agencies in Karnataka, Unpublished MVSc Thesis, Veterinary Extension Education, IVRI, Izatnagar.

Blau GL 2001 On assessing the construct validity of two multidimensional constructs: Occupational commitment and occupational entrenchment. Human Resource Management Review, 11: 279-298.

Bosco K 2000 Study on job performance and job satisfaction of Assistant Agricultural Officers in northern Districts of Karnataka, M.Sc. (Agri.) Thesis, University of Agricultural Sciences, Dharwad.

Chander M, Singh BP, Arya HPS, Mandape MK and Ravikumar S 2006 Status of Government run veterinary services in Uttar Pradesh: A case of Bareilly district. Indian Journal of Field Veteri- narians, 2 (1): 61-65.

Garrett HE 1981 Statistics in Psychology and Education, Vakils, Feffer and Simons Pvt. Ltd. Bombay.

Lazear EP and Rosen S 1981 Rank order tournaments as optimum labor contracts. Journal of Political Economy, 89(5): 841-864.

Nagananda C 2005 Study of organizational climate perception of Assistant Directors of Agriulture and Agricultural officers of KSDA, M.Sc. (Agri.) Thesis, University of Agricultural Sciences, Dharwad.

Nagananda C, Bheemappa A, Hirevenkanagoudar LV and Chandargi DM 2006 Organizational climate perception of officers of Karnataka State Department of Agriculture. Karnataka Journal of Agricultural Sciences, 19(4): 966-969.

Nataraju MS and Channegowda MS 1986 Some aspects about adopters of dairy innovations. Dairy Guide. 8 (2): 47 49.

National Commission on Agriculture 1976 Report, part 1, Review and Progress and part XI, Research, Education and Extension. Ministry of Agriculture and Irrigation, Govt. of India, New Delhi.

Nayak HS, Bajaj SS and Raut DR 1986 Problems of dairy farmers in Ahmednagar district Maharashtra. Maha. J. extn. Edu. 5: 107.

Popat MN, Bhatt MR and Patel AC 2002 Constraints felt by SMSs in job performance. Indian J. Exten. Edn, 38 (3\&4) : 203-206.

Punjabi MP, Kumar P, Sreeramulu P, and Ahuja V 2005 Livestock Service Delivery in Andhra Pradesh: Veterinari- 
ans' Perspective. Research Report, Nr. 05-07.

Rahman S 2011 Sustainability of DairyBased Self Help Groups (Shgs) In Assam: An Exploratory Study in Kamrup District. Phd Thesis, National Dairy Research Institute, Karnal.

Rao MR and Sastri PM 1984 Prospects and constraints in milk production. Journal of Indian Academy of applied Psychology, 9:73-79.

Rao SB 1987 A study of transfer of Dairy Production Technologies in chittoar district of Andhra Pradesh. PhD. Thesis, NDRI, Karnal.

Rath NC 1992 Job performance of SMS under T and $\mathrm{V}$ system in Orissa. Ph. D. Thesis, University of Agricultural Sciences, Bangalore.

Ravikumar S, Reddy KVR, Rao BS and Jagadeeswary V 2005 Constraints as perceived by livestock farmers in utilization of public veterinary services. XII Annual Conference of IAAVR2005 and $5^{\text {th }}$ Indian Veterinary Congress, Bikaner, Rajasthan.

Saharia KK 1990 A study on the Organizational Climate and Role performance as perceived by veterinarians for dairy development in Assam. National Dairy Research Institute, Karnal.

Sandika AL, Angadi JG, Hirevenkanagouda LV and Basavaraj H 2007 A study on organizational climate perception by veterinary officers and veterinary livestock inspectors of the department of animal husbandry and veterinary service, Karnataka. The Journal of Agricultural Sciences, 13 (2).

Sawant MN and Nikam TR 2007 Constraints Experienced by the Veterinari- ans while Communicating the Information. Indian Res. J. Ext. Edu. 7 (2\&3).

Sharma RK 1980 A study of Socio- Psychological and infrastructural constraints in the efficient Execution of ICDP. $\mathrm{PhD}$ Thesis. Kurukshetra University. Kurukshetra

Sohal TS 1985 Constraints in transfer of technologies. Transferable technologies for enhancing milk production. NDRI, Karnal.

Thippeswamaiah JM 1991 A study on the job performance and job satisfaction of Subject Matter Specialists working under NAEP. Karnataka. M.Sc. (Agri.) Thesis, University of Agricultural Sciences, Dharwad.

Thomas D and Rangnekar DV 2004 Responding to the increasing global demand for livestock products: Implication for the livelihood for the livestock producers in developing countries. Responding to the livestock revolution. British society of Animal Science. Occational publication 33: 1-36.

Venkatasubramaniam V and Ramchand 1992 Professional constraints perceived by field veterinarians of Tamil Nadu. Indian J. Dairy Sci.,45(2): 644-646.

Venkatsubramaniam V 1996 Constraints faced by dairy farmers of Tamil Nadu, Journal of Dairying, Food and Home Sciences, 15(1): 23-29.

Vroom VH 1964 Egoinvolvement, job satisfaction and job performance. Personal Psychology 15: 310 - 317 .

World Bank 1985 Agricultural Research and extension; an evaluation of the World bank experience, world bank, Washington. 